\title{
Tecnologias digitais da informação e comunicação: a garantia dos direitos civis relativo à propriedade do software
}

\section{Américo Augusto Nogueira Vieira}

\author{
Professor de Direito da UFPR. Pós-Doutorando \\ em Ciência da Informação da UFPB \\ Bacharel em Direito e em Matemática
}

\section{Guilherme Ataíde Dias}

\begin{abstract}
Doutor em Ciência da Informação (USP).PósDoutorado na UNESP/Marília.Professor Associado no Programa de Pós-Graduação em Ciência da Informação da UFPB .Bolsista de Produtividade em Pesquisa do CNPq
\end{abstract}

http://dx.doi.org/10.1590/1981-5344/1827

O que se denominam "direitos civis" nos Estados Unidos da América, tem, no Brasil, sua referência dada pelo artigo $5^{\circ}$ da Constituição brasileira e tal conjunto de direitos é denominado como: "Direitos e Garantias Fundamentais". O trabalho problematiza sobre o seguinte fato: apesar de haver a garantia constitucional da propriedade, se existe, de fato, nas leis federais brasileiras específicas (Lei de Software e Lei de Direitos Autorais), uma tolerância ou autorização a uma forma de "plágio de software". A pesquisa baseou-se na Constituição, na Convenção de Berna, nas leis federais e doutrinas jurídicas de propriedade intelectual, além de uma ampla bibliografia. Ao final, demonstra-se que há, sim, possibilidade de violação do direito de propriedade e, portanto, dos direitos civis, seja pela violação da própria Carta Política brasileira, seja pela interpretação equivocada da legislação federal específica.

Palavras-chaves: Direitos civis; Direito de propriedade; Propriedade intelectual; Constituição Brasileira; Software; Plágio. 


\title{
Digital information and communications technologies: the guarantee of civil rights on ownership of software
}

\begin{abstract}
The "civil rights" concept, as accepted in the Unites States of America legal system, is referenced in Brazil by Article Five of the Brazilian Constitution and the subsequent set of rights named "Fundamental Rights and Guarantees". This paper discusses the fact that: although there is a constitutional guarantee of property, in regard to specific Brazilian federal laws (Software and Authors' Right Law) it might arise a tolerance or authorization to a form of "software plagiarism." The research was based on the Constitution, the Berne Convention, Federal Laws and legal doctrines of intellectual property and further extensive bibliographic review. At the end, it is demonstrated that there is a possible infringement of the property rights (civil rights), by violating the Brazilian Constitution itself or through the misinterpretation of the specific federal legislation.
\end{abstract}

Keywords: Civil rights; Property rights; Intellectual property; Brazilian constitution; Software; Plagiarism.

Recebido em 11.06.2013 Aceito em 24.09.2013

\section{Introdução}

A comunidade científica, em geral, possui amplos interesses na área de Propriedade Intelectual, dado que há relevante produção desse tipo de bem intelectual por tal grupo. As proteções jurídicas "dadas" pelo Estado Brasileiro, em relação a esses interesses, materializam-se nos direitos de proteção ligados a: patentes, modelos de utilidade (por exemplo, pelo pessoal das engenharias), marcas, desenho industrial (por exemplo, pelo pessoal de áreas que envolvem design), proteção de software (por exemplo, pelo pessoal de áreas que envolvem Tecnologias Digitais de Informação e Comunicação (TDIC) - como Ciência da Informação e Ciência da Computação), etc., e, no âmbito mais geral, no que diz respeito ao Direito Autoral (artigos, livros, etc.). Entretanto, salvo os operadores do Direito ${ }^{1}$, não há um conhecimento, dessa comunidade científica, em caráter mais detalhado, da legislação que ampara tais direitos e uma discussão se realmente os direitos de propriedade ligados

\footnotetext{
${ }^{1}$ Os principais operadores do direito são os advogados, magistrados e promotores de justiça.
} 
aos bens do conhecimento estão efetivamente protegidos no ordenamento jurídico brasileiro. É, nesse diapasão, de apropriação dos conceitos e termos jurídicos, de elucidação e incitação à discussão do tema da propriedade intelectual e de correlacionar com vários aspectos dos direitos civis no Brasil, que se traz a lume a presente temática.

Tais direitos, ou pelo menos a previsão desses direitos, foram duramente conquistados (e não "dados"). O que deveria ser "dado" pelo Estado (e cremos não estar o Estado brasileiro cumprindo sua obrigação) é a proteção prevista pelo direito conquistado na Constituição Federal; mas tal como acontece em outros países, repetidamente os grupos, visando à permanente conservação do poder, violam a Carta Política, em nome de uma pretensa razão de Estado; ainda que esta terminologia de origem francesa não seja nunca proferida, dado que a simples menção ao rótulo "razões de Estado" seria uma confissão de violação frontal da Constituição Federal. Neste sentido, o artigo visa a dar início a uma série de discussões sobre direitos civis no Brasil e, no presente trabalho, em particular, começando pelos direitos civis de garantir a propriedade intelectual. Os pares da Academia, em geral, não possuem uma cultura de "discutir juridicamente seus objetos de estudo". Acontece que, em vários ramos do conhecimento, há uma questão que obriga essa relação mais próxima com o Direito: a Propriedade Intelectual. Assim, alguns pesquisadores brasileiros de Ciência da Informação (SANTOS; VASCONCELLOS; BRITTO, 2011; DIAS; VIDOTTI, 2012), vêm trazendo a lume tal questão do direito de propriedade voltado ao software e sua proteção no ordenamento jurídico brasileiro para toda a comunidade científica e não somente para os pesquisadores da área do Direito e seus operadores.

A Carta Política brasileira, de 1988, aponta taxativamente, em seu artigo 50, caput, a inviolabilidade do direito de propriedade aos brasileiros e estrangeiros residentes no país ${ }^{2}$. Naturalmente que pessoas físicas e jurídicas, nacionais ou estrangeiras, com domicílio no país, podem ser titulares, no Brasil, de direito de propriedade. Assim sendo, organizações como Apple, Google, Microsoft ${ }^{3}$, entre outros gigantes na área das Tecnologias Digitais da Informação e Comunicação, devem ter resguardados seus direitos de propriedade, desde que formalmente constituídos no Brasil, pois são invioláveis nos termos da Constituição. Também e principalmente os nacionais, igualmente detentores de direito de propriedade intelectual, devem ter seus direitos constitucionais resguardados. Neste sentido, 0 legislador brasileiro constitucional originário, além de apontar a inviolabilidade desse direito de propriedade no caput do artigo $5^{0}$ da Constituição Federal, entendeu necessário precisar o apontamento do peso

\footnotetext{
2 "Art. 50. Todos são iguais perante a lei, sem distinção de qualquer natureza, garantindo-se aos brasileiros e aos estrangeiros residentes no País a inviolabilidade do direito à vida, à liberdade, à igualdade, à segurança e à propriedade, nos termos seguintes:" (BRASIL, 1988).

3 Por exemplo, a gigante empresarial Microsoft, na forma da lei brasileira, em 1989, criou seu "braço brasileiro", através de empresa de responsabilidade limitada: Microsoft Informática Ltda., com domicílio à Av. Nações Unidas, 12.901 - Torre Norte - $31^{\circ}$ andar, CEP 04578-000, São Paulo, SP, Brasil. Disponível em: <http://www.microsoft.com/about/pt/br/informacoes institucionais.aspx>. Acesso em: 20 jan. 2013. No mesmo sentido, a Apple constitui pessoa jurídica no Brasil: Apple Computer Brasil Ltda., domiciliada à Av. Cidade Jardim, 400, $2^{\circ}$ andar, Jardim Paulistano, São Paulo, SP, CEP 01454901. Disponível em: <http://store.apple.com/br-smb/open/salespolicies\#topic-19 >. Acesso em: 20 jan. 2013.
} 
do direito de propriedade no inciso $\mathrm{XXII}^{4}$, no inciso $\mathrm{XXVII}^{5}$, no inciso $\mathrm{XXVIII}{ }^{6}$

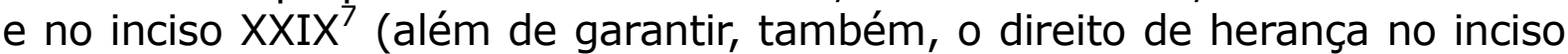
$\mathrm{XXX}^{8}$ ), e precisar o contrapeso desse direito de propriedade no inciso $\mathrm{XXIII}^{9}$, que é o apontamento da necessária função social da propriedade.

A este sistema de pesos e contrapesos há um agir cognitivo dos operadores de Direito, que é o sopesamento (ato de ponderar e/ou balancear os limites, ainda que não matematicamente precisos, do alcance de cada norma jurídica). Mas não só os operadores de direito devem refletir sobre tal questão; toda a comunidade científica e a sociedade em geral, em suas análises, poderão e deverão fazê-lo.

A pesquisa que deu origem ao presente artigo baseou-se na Constituição Federal de 1988, na Convenção de Berna, nas leis federais e doutrinas jurídicas de propriedade intelectual e em ampla bibliografia. Nesta pesquisa, adotamos uma perspectiva de sempre primarmos pelo respeito máximo à Carta Política, que, ao nosso entendimento, deve ser a referência jurídica maior a ser respeitada, salvaguarda para existência de efetivo Estado de Direito. Notório que nossa atual constituição, ou qualquer outra, poderia ser totalmente alterada pela via do surgimento de um novo Estado que venha a substituir o atual Estado Brasileiro. Entretanto, a via para modificar o status quo é fazer surgir um novo Estado por uma nova constituição; não é o caso de nos ombrearmos com maus governantes que roubam do povo seus direitos e garantias erigidos constitucionalmente. Neste sentido, devemos alertar que o "direito de propriedade" erigido em nossa atual Constituição (direito de que o ente privado, pessoa física ou jurídica, constitua propriedade oponível contra todos) é apenas balanceado pela "função social da propriedade" (também cláusula constitucional). Tal alerta se justifica, pois contrariamente ao entendimento de alguns, o direito de propriedade é a regra geral e o eventual interesse coletivo ou do Estado a ser albergado, com relação a esta mesma propriedade, é a exceção; somente podendo ser acolhida a pretensão de violação do direito constitucional de propriedade em situações excepcionais, que deverão ser demonstradas e, também, mediante prévia e justa indenização.

Finalmente, aponta-se que o trabalho problematiza a questão se há ou não há, nas leis federais brasileiras específicas (Lei de Software e Lei de Direitos Autorais), uma tolerância ou autorização a uma forma de "plágio de software", apesar de haver a já referida garantia constitucional

\footnotetext{
4 "XXII - é garantido o direito de propriedade;" (BRASIL, 1988).

5 "XXVII - aos autores pertence o direito exclusivo de utilização, publicação ou reprodução de suas obras, transmissível aos herdeiros pelo tempo que a lei fixar;" (BRASIL, 1988).

6 "XXVIII - são assegurados, nos termos da lei:

a) a proteção às participações individuais em obras coletivas e à reprodução da imagem e voz humanas, inclusive nas atividades desportivas;

b) o direito de fiscalização do aproveitamento econômico das obras que criarem ou de que participarem aos criadores, aos intérpretes e às respectivas representações sindicais e associativas;" (BRASIL, 1988).

7 "XXIX - a lei assegurará aos autores de inventos industriais privilégio temporário para sua utilização, bem como proteção às criações industriais, à propriedade das marcas, aos nomes de empresas e a outros signos distintivos, tendo em vista o interesse social e o desenvolvimento tecnológico e econômico do País;" (BRASIL, 1988).

8 "XXX - é garantido o direito de herança;" (BRASIL, 1988).

9 "XXIII - a propriedade atenderá a sua função social;" (BRASIL, 1988).
} 
da propriedade. Ainda neste sentido, objetiva-se, também, estabelecer uma relação direta e com fundamento constitucional, entre o direito/garantia de propriedade e a função pragmática deste direito/garantia, com relação à propriedade intelectual e, em particular, ao direito de propriedade de software, tanto aplicável ao direito dos nacionais quanto ao direito dos estrangeiros domiciliados legalmente no país.

\section{A questão do direito de propriedade intelectual no Brasil}

A Constituição Federal brasileira, de 1988, através dos representantes do povo, deixou claro que nossa opção política foi por um Estado Liberal, quando apôs, em seus dispositivos constitucionais, a garantia da propriedade (inciso XXII, do artigo 50, da Constituição Federal) e do direito de herança (inciso XXX, do artigo 50, da Constituição Federal), tal como o fez John Locke (2005, p. 407-409) em seu "Dois Tratados Sobre os Governos": "Embora a Terra e todas as criaturas inferiores sejam comuns a todos os homens, cada homem tem uma propriedade em sua própria pessoa. A esta nem tem direito algum além dele mesmo". Nesse sentido, Locke introduziu o efeito erga omnes (contra todos) no direito de propriedade; tal efeito é presentemente utilizado pacificamente na legislação brasileira, em relação ao direito de propriedade, seja esse bem material/tangível - como se dá, por exemplo, no direito a ser proprietário de um imóvel, tendo este sido devidamente registrado -, ou imaterial/intangível - como se dá, por exemplo, no direito das marcas e patentes (efeito do direito de propriedade que se denomina de exclusiva, tendo tal direito sido requerido no Instituto Nacional de Propriedade Industrial (INPI) $)^{10}$.

É mister apontar que o tipo de liberalismo adotado na Constituição Federal de 1988 é do tipo keynesiano ${ }^{11}$, pelo qual se admite a intervenção do Estado na Economia em certas situações especiais ${ }^{12}$. Vejamos uma das críticas de Keynes (1996, p. 66) ao liberalismo ortodoxo, o liberalismo original, ainda aguerrido ao laisser faire:

O celebrado otimismo da teoria econômica tradicional - que levou os economistas a serem considerados Cândidos, os quais, tendo-se retirado do mundo para cultivarem seus jardins, clamam que tudo caminha do melhor modo no melhor dos mundos possível, contanto que deixemos as coisas andarem sozinhas - tem como origem, no meu entender, o fato de não haver sido levado em conta o empecilho que uma insuficiência da demanda efetiva pode significar para a prosperidade, pois em uma sociedade que funciona de acordo com os postulados clássicos deveria existir uma tendência

10 Autarquia federal responsável pela concessão da proteção estatal de vários direitos de propriedade intelectual.

${ }^{11}$ Relativo às ponderações de John Maynard Keynes, em sua obra "A Teoria Geral do Emprego, dos Juros e da Moeda".

12 Como, por exemplo, na proteção da função social da propriedade, no controle ponderado do Estado na Economia, na possibilidade de o Estado amparar financeiramente as empresas; tal como ocorreu recentemente nos EUA no primeiro governo do Presidente Barack Obama. 
natural para o emprego ótimo dos recursos. Pode muito bem ser que a teoria clássica represente o caminho que a nossa economia, segundo o nosso desejo, deveria seguir, mas supor que na realidade ela assim se comporta é presumir que todas as dificuldades estejam removidas.

Esta opção pelo liberalismo keynesiano (o que admite situações excepcionais de intervenção do Estado na economia e não de qualquer liberalismo) pode ser vista em vários artigos da Constituição (tal como no artigo 50, em vários incisos, no artigo $1^{0}$, inciso $\mathrm{IV}^{13}$, artigo 170, em vários de seus incisos e no parágrafo único ${ }^{14}$, artigos $172^{15}, 173^{16}$ e $174^{17}$, artigo 150 no inciso $\mathrm{IV}^{18}$, etc.). Firmado sobre qual terreno jurídicoinstitucional estamos transitando, avançaremos na discussão sobre a cláusula pétrea ${ }^{19}$, que garante o direito de propriedade na Constituição.

O direito de propriedade, sendo garantia pétrea da Constituição Federal (conforme art. 50, caput e incisos XXII, XXVII, XXVIII, etc.), não pode ser alterado, suprimido e/ou interpretado restritivamente, salvo seu balanceamento pela função social da propriedade. Portanto, nossa missão é realizar ponderações acerca desse mecanismo de sopesamento. Notório que para garantir a efetiva soberania nacional, a necessidade de desenvolvimento do país, em caso de flagrante surgimento de obstáculos a este desenvolvimento, entre outras questões (guerras, estado de sítio, etc. ${ }^{20}$ ), seria possível, em tese, dar maior ênfase à função social da propriedade, em detrimento da garantia do direito de propriedade.

Seguindo este entendimento, não são estas as situações excepcionais em que nos encontramos, dado que o Estado Brasileiro

\footnotetext{
13 "IV - os valores sociais do trabalho e da livre iniciativa;" (BRASIL, 1988).

14 "Art. 170. A ordem econômica, fundada na valorização do trabalho humano e na livre iniciativa, tem por fim assegurar a todos existência digna, conforme os ditames da justiça social, observados os seguintes princípios:

II - propriedade privada;

III - função social da propriedade;

IV - livre concorrência;

$\checkmark$ - defesa do consumidor;

VIII - busca do pleno emprego;

IX - tratamento favorecido para as empresas de pequeno porte constituídas sob as leis brasileiras e que tenham sua sede e administração no País.

Parágrafo único. É assegurado a todos o livre exercício de qualquer atividade econômica, independentemente de autorização de órgãos públicos, salvo nos casos previstos em lei." (BRASIL, 1988).

15 "Art. 172. A lei disciplinará, com base no interesse nacional, os investimentos de capital estrangeiro, incentivará os reinvestimentos e regulará a remessa de lucros." (BRASIL, 1988).

16 "Art. 173. Ressalvados os casos previstos nesta Constituição, a exploração direta de atividade econômica pelo Estado só será permitida quando necessária aos imperativos da segurança nacional ou a relevante interesse coletivo, conforme definidos em lei." (BRASIL, 1988).

17 "Art. 174. Como agente normativo e regulador da atividade econômica, o Estado exercerá, na forma da lei, as funções de fiscalização, incentivo e planejamento, sendo este determinante para o setor público e indicativo para o setor privado." (BRASIL, 1988).

18 "Art. 150. Sem prejuízo de outras garantias asseguradas ao contribuinte, é vedado à União, aos Estados, ao Distrito Federal e aos Municípios:

IV - utilizar tributo com efeito de confisco;" (BRASIL, 1988).

19 Cláusulas pétreas são cláusulas constitucionais brasileiras que não podem ser modificadas por quaisquer legisladores após a promulgação da Carta Política, consoante o previsto no artigo 60 , § 40, da Constituição Federal e que é também entendimento consolidado pelo Supremo Tribunal Federal brasileiro.

20 "Art. 138. O decreto do estado de sítio indicará sua duração, as normas necessárias a sua execução e_as garantias constitucionais que ficarão suspensas, e, depois de publicado, o Presidente da República designará o executor das medidas específicas e as áreas abrangidas." (BRASIL, 1988).
} 
continua a garantir, no presente momento, o direito de patentes a inventos de estrangeiros que foram regularmente requeridos no INPI. Portanto, falecem quaisquer argumentos de que há em curso uma situação extraordinária para se aumentar o peso da função social da propriedade, em desfavor do peso do direito de propriedade, também constitucionalmente garantido em cláusula pétrea. Tal argumento supracitado é inescapável para haver o devido balanceamento dos princípios-garantias.

O significado de uma constituição é que: esta Lei Maior governa os governos. Isto é, impede que os temporários agentes do poder alterem as cláusulas contratuais, firmadas entre o Estado e os súditos, salvo as alterações através dos próprios comandos estabelecidos nesta mesma Constituição; recordemos rapidamente o espírito do contrato social em Rousseau (1932, p. 24):

Encontrar uma forma de associação que defenda e proteja de toda força comum a pessoa e os bens de cada associado, e pela qual, cada um, unindo-se a todos, não obedeça senão a si mesmo, e permaneça tão livre como anteriormente. Tal é o problema fundamental cuja solução é dada pelo contrato social.

Ainda no mesmo sentido, no caso do ordenamento jurídico brasileiro, as já referenciadas cláusulas pétreas são irremovíveis, não podendo ser inclusive alvo de Propostas de Emendas Constitucionais (PEC) que as limitem ou as excluam ${ }^{21}$.

Com fundamento no Princípio da Hierarquia das Normas Jurídicas, não pode o legislador infraconstitucional alterar e/ou adulterar os princípios-garantias pétreos, dentre os quais o princípio-garantia relativo à propriedade (o equivalente ao direito civil de alguém poder possuir propriedades e que tal direito possa ser oponível contra todos). A Constituição Brasileira não é imutável, ou seja, é passível de Emendas Constitucionais. Entretanto, pode ser classificada de super-rígida quanto à possibilidade dessa mutabilidade, dado que: há parte da Constituição Federal que não pode ser suprimida, modificada visando à restrição (ou, em nosso entendimento, mesmo interpretada restritivamente, pois, então, haveria a referida mutabilidade de cláusula pétrea praticada pelo Poder Judiciário ou Pelo Poder Executivo - pela via da interpretação restritiva -, e não pelo Poder Legislativo; o que ainda seria muito mais contrário ao texto da Carta Política e os fins que se buscaram com a mesma).

Não obstante os argumentos já expostos, como reforço à defesa de nosso

entenimento de não se poder realizar interpretação restritiva, aponta-se, também, que a CF no art. $5^{\circ}, \S 1^{\circ}$, define que os direitos e garantias fundamentais têm aplicação imediata ${ }^{22}$ e 0 art. $5^{\circ}, \S 2^{\circ}$, da Constituição admite, ainda, a inserção

21 "Art. 60. A Constituição poderá ser emendada mediante proposta:

$\S 40$. Não será objeto de deliberação a proposta de emenda tendente a abolir:

IV - os direitos e garantias individuais." (BRASIL, 1988).

22 "§ $1^{\circ}$. As normas definidoras dos direitos e garantias fundamentais têm aplicação imediata." (BRASIL, 1988). 
de outros direitos e garantias ${ }^{23}$, além dos ali elencados. Notório que a leitura atenta do $\S 2$ acima aponta

poder haver a inclusão de outros direitos e garantias, permitindo o adicionamento e, dessa forma, fazendo emergir um "Princípio Constitucional de Expansão aos Direitos e Garantias do art. 5ำ da Constituição Federal", portanto, um princípio de caráter expansivo ou aditivo (e não o contrário, uma interpretação restritiva e/ou subtrativa).

Sendo assim, não pode haver a detalhada e eficaz proteção de marcas e patentes, como vemos ocorrer, que impedem, por exemplo, uma cópia ilegal do invento em face do direito de propriedade (direito de propriedade denominado, nesta seara jurídica, de exclusiva) e não haver o equivalente eficaz de proteção ao direito de propriedade, que se exerce erga omnes ao direito de propriedade aplicado ao software. As normas principais de Marcas e Patentes encontram-se na Lei Federal 9.279/96, já a proteção ao software encontra-se na Lei Federal 9.609/98; no próximo item, discorreremos sobre a ineficaz proteção ao software, cotejando tal ineficácia com os dispositivos legais infraconstitucionais.

\section{Proteção real ao software ou violação da Carta Política}

O artigo primeiro da Lei de Software, no Brasil, define o que seja um programa de computador. Nesta definição, há a seguinte expressão (BRASIL, 1998a): "para fazê-los funcionar de modo e para fins determinados"24. Portanto, os "fins a que se destina" o software (caráter pragmático do invento intelectual) é o elemento caracterizador do mesmo. Acontece que o legislador infraconstitucional brasileiro também apôs, no mesmo dispositivo legal (Lei Federal 9.609/98 - Lei do Software), uma "equivalência a legislação de Direito Autoral" (BRASIL, 1998a): "Art. 20. O regime de proteção à propriedade intelectual de programa de computador é o conferido às obras literárias pela legislação de direitos autorais e conexos vigentes no País, observado o disposto nesta Lei.". Veremos mais adiante que: a não observação doutrinária com relação aos dispositivos infraconstitucionais já existentes e a não observância (e/ou interpretação conforme) estrita ao direito de propriedade erigido constitucionalmente, faz com que se abandone a já transcrita expressão: "para fazê-los funcionar de modo e para fins determinados" (BRASIL, 1998a) e que se termine por tolerar uma forma de plágio de software.

Para melhor esclarecimento de todos, retomemos as categorias de conhecimento da Semiótica (sintaxe, semântica e pragmática): não é considerada violação de direito de propriedade intelectual, se ocorrer que dois ou mais programas de computador, ainda que visando ao mesmo fim prático (mesmo caráter pragmático), tenham sintaxes distintas. Tomemos como exemplo, para fins meramente expositivos, que: se um determinado

\footnotetext{
23 "§ $2^{\circ}$ - Os direitos e garantias expressos nesta Constituição não excluem outros decorrentes do regime e dos princípios por ela adotados, ou dos tratados internacionais em que a República Federativa do Brasil seja parte." (BRASIL, 1988).

24 "Art. 10. Programa de computador é a expressão de um conjunto organizado de instruções em linguagem natural ou codificada, contida em suporte físico de qualquer natureza, de emprego necessário em máquinas automáticas de tratamento da informação, dispositivos, instrumentos ou equipamentos periféricos, baseados em técnica digital ou análoga, para fazê-los funcionar de modo e para fins determinados" (BRASIL, 1998).
} 
programa de computador determina que um dispositivo computacional adicione dois números inteiros em uma certa linguagem de computador e outro programa, utilizando outra linguagem de computador, faça o mesmo, então consideram-se programas diferentes, pela simples análise da sintaxe do programa fonte ${ }^{25}$.Vejamos os exemplos de programas, nas figuras a seguir:

Figura 1- Programa Soma de dois números inteiros Linguagem Pascal

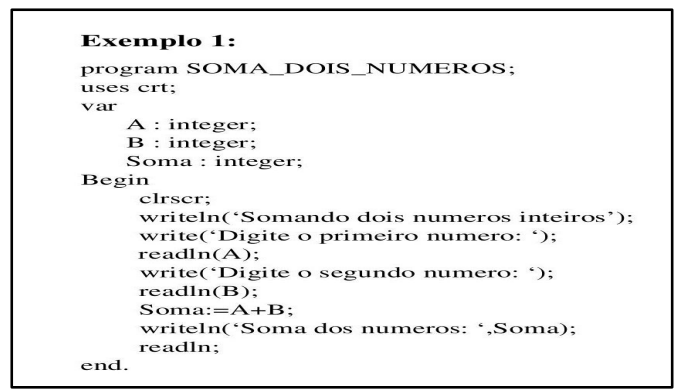

Fonte: (ALVES, 2013).

Figura 2 - Programa Soma de dois números inteiros na Linguagem C

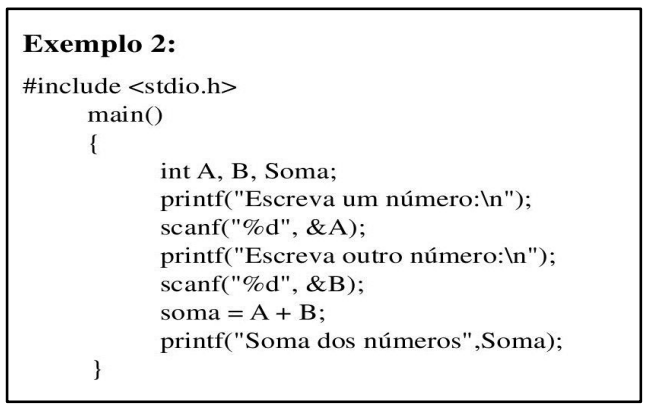

Fonte: (LOBO, 2004).
Figura 3 - Programa Soma de dois números inteiros na Linguagem Java

Nosso conjunto de exemplos nas figuras anteriores é meramente didático para fins de entendimento da aplicação das categorias da Semiótica (sintaxe, semântica e pragmática) no entorno de nossas discussões. Sabemos que não haveria de qualquer modo a proteção desses programas aqui utilizados como exemplos, em face de que, nesses casos concretos, a única coisa que eles fazem é a "soma de dois inteiros" (sob pena de estarmos protegendo operações matemáticas). Entretanto, podemos facilmente transpor o mero conjunto de exemplos didáticos e imaginar que os ardis aqui apontados poderiam ser utilizados em qualquer tipo de software; e é nesse sentido que realizamos a presente exemplificação. Os três programas fontes anteriores fazem essencialmente a mesma coisa (mesmo fim): somam dois números inteiros A e B que foram introduzidos. As sintaxes de exibição (formas de representação) são diferentes, por utilizarem três "idiomas computacionais" (linguagens de

\footnotetext{
${ }^{25}$ Programa fonte ou "código fonte"; após tal código fonte ser compilado, através de outro software denominado compilador, é que se diz que este foi transformado em software, isto é, em um "programa executável".
} 
programação) diferentes. Mas, são uma mesma coisa; apesar de o ordenamento jurídico brasileiro não classificar (ou interpretar) tal "identidade de programas" como plágio, em nosso entendimento, é isto o que no fundo acontece: um programa é plágio do outro. Pois, todos possuem a mesma funcionalidade (identidade do caráter pragmático), ambos possuem o mesmo caráter lógico e/ou matemático que subjaz a sistemática computacional (identidade semântica), diferindo apenas no caráter sintático, isto é: uso de linguagens computacionais diferentes: Java, Pascal e C; ou, ainda, como ocorre com os idiomas ou com idiomas que possuem alfabetos diferentes e/ou sistemas escriturais diferentes, tais como a distinção entre os caracteres escriturais árabes, chineses e latinos. Não obstante a diferenciação se dar apenas pela sintaxe nos programasexemplos anteriores, ocorre, no Brasil, tal diferenciação sintática ser aceita como diferenciadora na propriedade intelectual aplicada ao software e impedidor de ser considerado plágio situações semelhantes aos três programas-exemplos.

Vejamos o que ocorreria com certa peça de maquinário, se possuísse um mesmo fim (tal como ser uma peça de apoio de carga, caráter pragmático) e mesmo sistemática/lógica de construção (ser apenas um paralelepípedo, caráter semântico), mas fosse apenas representada por sintaxes diferentes (o que poderia fazer parecer que são três peças distintas, o que não é o caso). Vejamos três exemplos representando desenhos de "peças" a seguir:

Figura 4 - Paralelepípedo com rasgo passante representado com sintaxe com 1 ponto de fuga (PF)

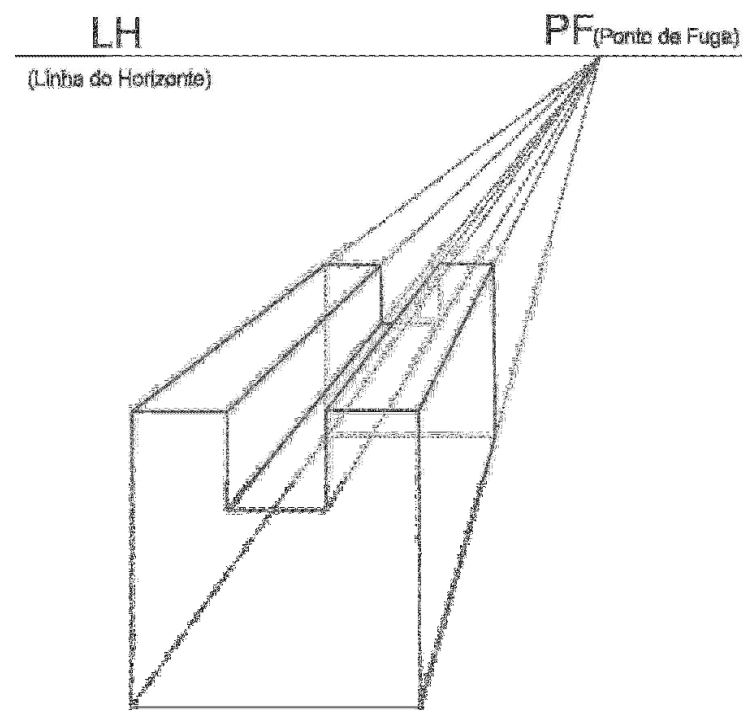

Fonte: (VIEIRA; PALA, 2013). 
Figura 5 - Paralelepípedo com rasgo passante representado com sintaxe com 2 pontos de fuga (PF1 e PF2)

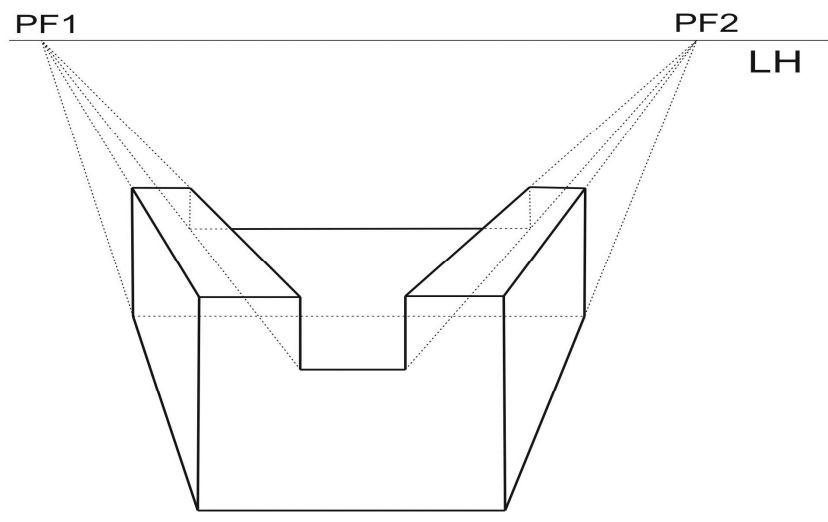

Fonte: (VIEIRA; PALA, 2013).

Figura 6 - Paralelepípedo com rasgo passante representado com sintaxe com 3 pontos de fuga (PF1, PF2, PF3)

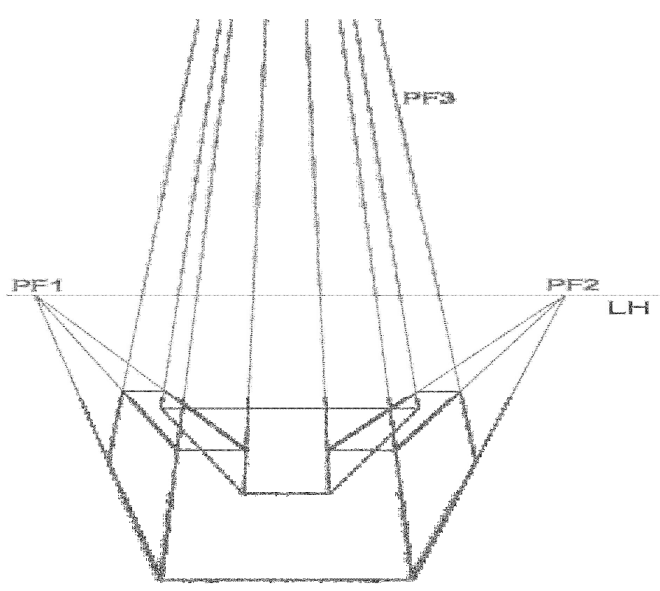

Fonte: (VIEIRA; pALA, 2013).

Ainda que em nossos exemplos gráficos anteriores tenhamos nos utilizado de uma forma extremamente simples, um paralelepípedo, tal distinção entre as três peças-exemplo representadas por sintaxes diferentes, no INPI, seria realizada uma inspeção, por comparação a outros pedidos de patentes anteriores, através dos fins que se destinam o invento (inspeção pelo caráter pragmático), consoante o previsto no artigo 41 da Lei Federal 9.279/96 (BRASIL, 1996): "Art. 41. A extensão da proteção conferida pela patente será determinada pelo teor das reivindicações, interpretado com base no relatório descritivo e nos desenhos". Notem que, além da sintaxe (indicado pela expressão: "e nos desenhos"), também, e principalmente, é o teor das reivindicações aposto no relatório descritivo (os fins a que se destina o invento, portanto, caráter pragmático) que distingue um invento de outro e, se haverá ou não haverá, a proteção da propriedade conferida pelo Estado. Notem que o caput do artigo 42 (e também o $§ 1^{\circ}$ ) da Lei Federal 9.279/96 aponta(m) 
implicitamente o já mencionado efeito erga omnes (BRASIL, 1996): "Art. 42. A patente confere ao seu titular o direito de impedir terceiro, sem o seu consentimento, de produzir, usar, colocar à venda, vender ou importar com estes propósitos:". Também o aspecto criminal da contrafação de patentes aponta o mesmo, que se deve atentar para o caráter pragmático, consoante o artigo 186 da Lei Federal 9.279/96 (BRASIL, 1996): "Art. 186. Os crimes deste Capítulo caracterizam-se ainda que a violação não atinja todas as reivindicações da patente ou se restrinja à utilização de meios equivalentes ao objeto da patente".

Fica claro que, no caso das patentes e dos modelos de utilidade em face de ter de haver, mediante o previsto no artigo 41 da Lei Federal 9.279/96 (já transcrito anteriormente), distinção pela sintaxe (análise dos desenhos) e, também, pela pragmática (análise do relatório descritivo), exigências cumulativas, nosso exemplo do paralelepípedo, caso houvesse reprodução não autorizada (com tentativa de engodo pela sintaxe) seria uma violação do direito de propriedade intelectual: uma contrafação. Já no caso do software, cuja inspeção se dá de forma, a nosso ver, precária, somente pela sintaxe (como vimos nos exemplos de programas de "soma de dois números inteiros"), é fácil a contrafação ou plágio ou, de forma mais genérica, a violação do direito de propriedade intelectual. Um ardil equivalente no Direito Autoral, visando ao plágio, seria pegar o livro "Os Irmãos Karamazov" de Fiódor Dostoiévski, em russo original, portanto, em outro tipo de alfabeto, o cirílico (e não o alfabeto latino), traduzir para o português e trocar o nome dos personagens principais: Ivan (um escritor); Alexi (ou Aliocha, um padre); e Dmitri (um militar), esses primeiros irmãos e o pai Fiódor, para: Zezinho, Huguinho e Lusinho e o pai Donald; tal como fizemos nos três exemplos de programas fontes da "soma de dois números". Admitir tal violação de propriedade no direito autoral não seria minimamente aceitável, mas está a ocorrer na questão de proteção de propriedade do software, conforme já expusemos.

\section{Considerações Finais}

Há ineficácia da legislação brasileira infraconstitucional na proteção dos métodos e técnicas embutidos (e redigidos) em um software, consoante à previsão de proteção de propriedade aposta na Carta Política; tal situação, que fere o direito de propriedade erigido constitucionalmente, deve-se ao fato de uma determinada ação computacional poder ser implementada de forma que o resultado da computação seja idêntica (identidade pragmática), mesmo que o software associado a esta ação esteja codificado de outra forma (distinção de sintaxe). Admitir isso é o equivalente a admitir que a mera troca da posição de parágrafos, associada com a tradução de um texto de um idioma para outro, geraria uma obra literária nova. Não vale tal ardil para as obras literárias (como já expusemos em nossa analogia em "Os Irmãos Karamazov") e não deveria valer, também, para o software. Se, por absurdo, admitíssemos a mera troca de ordem de parágrafos e combinássemos que vale a mera troca de um idioma para outro, e isso pudesse ser válido como um artigo científico novo/original, então já 
teríamos, como comunidade científica, admitido o plágio nos artigos científicos e demais trabalhos acadêmicos.

Não obstante o já exposto, entendemos que, também, há o estratégico interesse

do Estado brasileiro em não enfrentar seriamente a questão de violação de direitos de Propriedade Intelectual relativo ao software, em face de o Brasil não ser grande produtor desse produto; mas não pode o Estado Brasileiro, em face de uma mera estratégia econômica, transformar nossa Constituição da República em letra morta, no que tange ao direito de propriedade.

Destes e de outros fatos e fundamentos é que se consolida uma grande e emergente necessidade da sociedade brasileira (e dos estrangeiros interessados em terem suas propriedades protegidas também no Brasil) e, também, da Academia como um todo (não só do ramo estritamente jurídico), repensar o sistema de proteção da Propriedade Intelectual no Brasil. No caso da Ciência da Informação e das demais áreas envolvidas com Tecnologia da Informação, é fundamental o envolvimento com Propriedade Intelectual nas questões associadas com as Tecnologias Digitais da Informação e Comunicação (TDIC), em face do necessário estímulo ao desenvolvimento de produtos pelos nossos formandos e pela própria comunidade acadêmica como um todo. Nesse sentido, já há esforços de aumentar a participação da Ciência da Informação na discussão acerca da propriedade intelectual, tais como pode ser ver em Dias e Vidotti $(2011$; 2012) e Santos, Vasconcellos e Britto (2011).

Uma redefinição normativa ao nível infraconstitucional, no Brasil, se faz necessária e urgente, de modo que os limites da proteção dos programas de computador estejam bem definidos e dissociados do Direito Autoral (seja pela não proteção efetiva no sentido da cópia/plágio, seja pela proteção excessiva no sentido do tempo de 50 anos), modificando-se os olhares para um caráter econômico do software. Para isso, devem ocorrer mudanças nas normas infraconstitucionais, que proporcionem 0 fortalecimento do software dentro da Propriedade Industrial, com características específicas que venham a possibilitar sua submissão ao regime de patentes, que, como vimos, tem seu direito constitucional de propriedade bem melhor protegido em solo brasileiro. Nesse sentido, a universidade é uma das mais legítimas instituições para influenciar as fontes materiais (tal como a opinião pública) e para o convencimento de nossos legisladores em respeitar o que prevê nossa Carta Política.

O direito de propriedade que aqui defendemos, foi denominado por John Locke (2005) de "direitos civis" (relativos à liberdade, à vida ou à propriedade) e tal uso da denominação "direitos civis" (ou "civil rights") foi popularizado pelo povo norte-americano; é, nesse sentido, que se faz um chamamento à Academia como um todo para esposar nossas teses.

Finalmente, apontamos aos colegas pesquisadores que um maior cotejamento da legislação infraconstitucional vigente (Lei do Software e Lei de Direito Autoral) com o anuído pelo Brasil na Convenção de Berna, permitiria, ainda, a percepção de outras discrepâncias ou inconsistências 
jurídicas no plano de proteção à propriedade intelectual com relação ao software. No mesmo sentido, a revisão da já revogada Lei 7.646/87 (antiga Lei do Software), em particular seu art. $10^{\circ}$.

\section{Referências}

ALVES, V. Engenharia de software e projeto de desenvolvimento de Software. USISINOS: Blog do Prof. D.Sc. Sérgio Crespo. 2013. Disponível em: <http://professor.unisinos.br/wp/crespo/engenharia-de-software-eproj-de-desenv-de-soft/>. Acesso em: 2 fev. 2013.

BARTOlOMEU, I. Programa básico para calcular a soma de 2 números inteiros. Site Web Designer. 2010. Disponível em: <http://isdesignerwebdesigner.blogspot.com.br/2010/11/programa-basico-para-calcularsoma-de-2.html>. Acesso em: 8 fev. 2013.

BRASIL. Constituição (1988). Constituição da República Federativa do Brasil. Diário Oficial da União, 5 out. 1988. Disponível em: $<$ http://www.planalto.gov.br/ccivil 03/constituicao/constituicao.htm>. Acesso em: 19 fev. 2012.

BRASIL. Decreto no 1.355, de 30 de dezembro 1994. Promulga a Ata Final que Incorpora os Resultados da Rodada Uruguai de Negociações Comerciais Multilaterais do GATT. Diário Oficial da União, 31 dez. 1994. Disponível em: <http://www.planalto.gov.br/ccivil_03/decreto/Antigos/D1355.htm>. Acesso em: 19 fev. 2012. Em anexo, ao link do Decreto, Ata do Acordo TRIPs da OMC (antigo GATT), disponível em: $<$ http://www.planalto.gov.br/ccivil 03/decreto/19901994/anexo/and1355-94.pdf > (p. 406 e seguintes).

BRASIL. Decreto $N^{\circ}$ 75.699, de 6 de maio de 1975. Promulga a Convenção de Berna para a Proteção das Obras Literárias e Artísticas, de 9 de setembro de 1886, Revista em Paris, a 24 de julho de 1971. Diário Oficial da União, 9 mai. 1975. Disponível em: $<$ http://www.cultura.gov.br/site/wp-content/uploads/2007/10/decreto75699.pdf>. Acesso em: 19 fev. 2012.

BRASIL. Lei No 9.279, de 14 de maio de 1996. Regula direitos e obrigações relativos à propriedade industrial. Diário Oficial da União, 15 mai. $1996 . \quad$ Disponível em: <http://www.planalto.gov.br/ccivil 03/leis/L9279.htm>. Acesso em: 19 fev. 2012.

BRASIL. Lei No 9.609, de 19 de fevereiro de 1998. 1998a. Dispõe sobre a proteção da propriedade intelectual de programa de computador, sua comercialização no País, e dá outras providências. Diário Oficial da União, 25 fev. $1998 . \quad$ Disponível em: <http://www.planalto.gov.br/ccivil_03/leis/L9609.htm>. Acesso em: 19 fev. 2012. 
BRASIL. Lei No 9.610, de 19 de fevereiro de 1998. 1998b. Altera, atualiza e consolida a legislação sobre direitos autorais e dá outras providências. Diário Oficial da União, 20 fev. 1998. Disponível em: <http://www.planalto.gov.br/ccivil 03/leis/L9610.htm>. Acesso em: 19 fev. 2012.

DIAS, G. A.; VIDOTTI, S. A. B. G. O direito da propriedade intelectual: relações com os entregáveis da Arquitetura da Informação. Perspectivas em Gestão \& Conhecimento, João Pessoa, v. 1, n. especial, p. 73-85, out. 2011. Disponível

em: < http://periodicos.ufpb.br/ojs2/index.php/pgc/article/view/10825/6100>. Acesso em: 14 maio 2013.

DIAS, G. A.; VIDOTTI, S. A. B. G. Arquitetura da informação no ambiente digital: avaliando as relações com o Direito da Propriedade Intelectual. Informação \& Sociedade: Estudos, João Pessoa, v. 22, n. 3, p. 115-132, set./dez. $2012 . \quad$ Disponível em: $<$ http://periodicos.ufpb.br/ojs2/index.php/ies/article/view/14131/8581>. Acesso em: 14 maio 2013.

DOSTOIÉVSKI, F. M. Os Irmãos Karamazov. São Paulo: Editora 34, 2008. $2 \mathrm{v}$.

KEYNES, J. M. A teoria geral do emprego do juro e da moeda. São Paulo: Nova Cultural, 1996. (Coleção Os Economistas).

LOBO, F. Programação Imperativa. Blog do Departamento de Engenharia Electrónica e Informática da Universidade do Algarve. 2003. Disponível em: <http://intranet.deei.fct.ualg.pt/PI flobo/teorica4.html>. Acesso em: 19 fev. 2012.

LOCKE, J. Dois tratados sobre o governo. Trad. Julio Fisher. São Paulo: Martins Fontes. 2005.

ROUSSEAU, J.-J. Do contrato social. São Paulo: e-books brasil.com, 2002. Disponível em: < http://www.cfh.ufsc.br/ w wfil/contrato.pdf>. Acesso em: 20 jan. 2013.

SANTOS, E. V. dos; VASCONCELLOS, A. G.; BRITTO, A. L. S. A inserção do tema da propriedade intelectual na Área de Ciência da Informação: uma análise sob o ponto de vista do periódico "Ciência da Informação". In: CONGRESSO BRASILEIRO DE BIBLIOTECONOMIA, DOCUMENTAÇÃO E CIÊNCIA DA INFORMAÇÃO, 24., 2011, Maceió. Sistemas de Informação, Multiculturalidade e Inclusão Social. São Paulo: FEBAB, 2011. p. 1-12. Disponível em: < http://www.febab.org.br/congressos/index.php/cbbd/xxiv/paper/view/5 49/353 >. Acesso em: 14 de mai. 2013.

VIEIRA, A. A. N.; PALA, I. de O. L. Paralelepípedos com rasgos passantes. mimeo. 2013. il. 